GRADIATION\&APPLICATIONS

ISSN 2466-4294 (online) | rad-journal.org

Vol. 2 | Issue 1 | pp. $46-52$

doi: 10.21175/RadJ.2017.01.010

Original research paper

\title{
REMOTE SENSING OF THE INFLUENCE OF BIOTIC STRESS ON PLANT BIOPHYSICAL VARIABLES*
}

\author{
Dora Krezhova $^{\text {1**}^{*}}$, Svetla Maneva ${ }^{2}$, Nikolay Petrov², Kalinka Velichkova ${ }^{3}$ \\ ${ }^{1}$ Space Research and Technology Institute, Bulgarian Academy of Sciences, Sofia, Bulgaria \\ 2Institute of Soil Science, Agrotechnology and Plant Protection, Bulgarian Agricultural Academy, Sofia, Bulgaria \\ 3University of Mining and Geology "St. Ivan Rilski”, Sofia, Bulgaria
}

\begin{abstract}
Hyperspectral remote sensing provides for significant advancement in the evaluation of the subtle changes in biophysical and biochemical attributes of the crop plants. Accurate estimates of leaf pigments, nitrogen, dry matter, water content, and leaf area index (LAI) from remotely sensed data can assist in determining the vegetation physiological state. In this paper, hyperspectral remote sensing measurements of the leaf reflectance were applied for assessing the effect of biotic stress (viral infection) on the spectral behaviour and biophysical variables of young potato plants, cultivar Agata, infected with Potato Virus Y (PVY). Spectral reflectance data were collected by means of a portable fiber-optics spectrometer in the visible and near infrared spectral ranges (350-1100 $\mathrm{nm}$ ) with a spectral resolution of $1.5 \mathrm{~nm}$. For the assessment of differences between the reflectance data of healthy and infected plant data processing techniques, such as Student's t-test, first derivative analyses, and estimation of vegetation indices, were applied. The analyses were performed in green, red, red edge and near infrared spectral ranges (450$850 \mathrm{~nm})$ where the differences were the most significant and give information about changes in the chlorophyll and pigment content, moisture content, cells structures, and plant stress. Several vegetation indices (NDVI - Normalized Difference Vegetation Index, $f_{D}$ - Disease Index, SR -Simple Ratio, TCARI - Transformed Chlorophyll Absorption Reflectance Index, etc.) were computed and the best results for assessing the changes in the physiological state of the plants gave TCARI. A strong relationship was found between the results of the spectral analyses and the serological test DAS-ELISA was applied to assess the presence and the degree of the PVY infection.
\end{abstract}

Key words: Remote sensing, hyperspectral leaf reflectance, biophysical variables, viral infection, Potato Virus Y (PVY), DAS-ELISA test

\section{INTRODUCTION}

Remote sensing applications in environmental research are the basis for advanced Earth observation datasets used in environmental monitoring and ecological research. For many purposes, remote sensing techniques provide means of measuring the characteristics of the objects on the Earth surface and for detecting environmental changes that occur as a result of human activities or natural processes [1], [2]. Recently high spectral resolution sensors have been developed, which allow new and more advanced applications in agriculture - spectral discrimination of crops and their genotypes [3], quantitative estimation of different biophysical and biochemical parameters through empirical and physical modelling [4], [5], assessing of abiotic and biotic stresses [6]-[8].

The hyperspectral sensors and technologies used improve significantly the capability to gather information through measuring the reflected and emitted electromagnetic radiation in the ultraviolet, visible (VIS), infrared, and microwave ranges [9]. Hyperspectral remote sensing (HRS) is based on the examination of many contiguous narrowly defined spectral channels (less than $10 \mathrm{~nm}$ ) and has been found to be superior to conventional broadband spectral remote sensing [10]. HRS in large number of continuous narrow bands provides significant advancement in understanding the subtle changes in biophysical and biochemical parameters of the plants and their different physiological processes that can be useful for monitoring and predicting short and longterm changes of ecosystems [11], [12]. It is an automatic, quick and non-destructive method of assessing plant growth parameters and nutrient levels in crop plant.

Spectral reflectance registered by remote sensing sensors gives information on an object without physical contact, by measuring the electromagnetic energy reflected/backscattered or emitted by the surface of the Earth. Unique spectral characteristics of vegetation are what make biophysical remote sensing possible.

\footnotetext{
* The paper was presented at the Fourth International Conference on Radiation and Applications in Various Fields of Research (RAD 2016), Niš, Serbia, 2016.

**dora.krezhova@gmail.com
} 
D. Krezhova et al., Remote Sensing of the Influence of Biotic Stress..., Rad. Applic., 2017, 2, 1, 46-52

Vegetation, because of its chemical and structural characteristics, absorbs, reflects, and transmits electromagnetic radiation in a very different manner than other natural and anthropogenic surfaces [13]. Because leaf spectral reflectance is a function of the illumination conditions, tissue optical properties and biochemical content (chlorophyll - Chl, water, dry matter, etc.) it may be used to collect information on some fundamental biophysical variables such as colour, vegetation biomass, vegetation chlorophyll absorption characteristics, vegetation moisture content, soil moisture content, temperature and texture/surface roughness [14], [15]. Hybrid variables can be derived from fundamental variables (e.g., vegetation stress can be derived from vegetation chlorophyll absorption characteristics and moisture content) [16].

The contrast between Chl absorption of VIS wavelengths and strong reflectance in the near infrared (NIR) spectral range aid in discriminating plant types and have resulted in the development of numerous vegetation indices (VI's) that provide a means of quantitatively measuring certain biophysical parameters [16], [17]. VI's are mathematical derivatives of spectral reflectance and have been developed as the combination of various wavebands (mostly in VIS and NIR regions of electromagnetic spectrum) that related to various canopy parameters. Spectral Vi's constitute a simple and convenient approach to extract information from remotely sensed data, due to their ease of use, which facilitates the processing and analysis of large amounts of data [18].

The red-edge position of the reflectance spectra can be used as a measure to estimate foliar chlorophyll or nitrogen content. The red edge represents the region of abrupt change in leaf reflectance between $680 \mathrm{~nm}$ and $780 \mathrm{~nm}$ caused by the combined effects of strong Chl absorption in the red and leaf internal scattering in the NIR spectral ranges [19]. Increasing in the amount of chlorophyll, results in a change of the major Chl absorption feature centered around $680 \mathrm{~nm}$ causing a shift in the slope and red edge position towards the longer wavelengths [20].

In this study the object of the investigations is potato plants because the potato is a very important crop - fourth in production and fifth in area among crop plants grown for human consumption worldwide. Potato is being appreciated for its nutritional value as well as its uses in the starch and food processing industry [21]. Potato is susceptible to many diseases (viruses, bacteria and fungi) and pests, and the amount of chemical pesticides applied annually to this crop is greater than that of any other food crop. About 40 viruses are known to affect the potato crop [22] Potato virus Y (PVY) causes the most significant yield loss in potato, wherever it is cultivated [23], [24].

In this paper the application of remote sensing measurements of leaf spectral reflectance in VIS and NIR spectral ranges for assessing the effect of adverse environmental condition (viral infection caused by Potato Virus Y) on the spectral behavior and biophysical variables of young potato plants is discussed. For the analyses different data processing techniques have been used to reduce data dimension and to minimize the information redundancy.

\section{MATERIALS AND METHODS}

\subsection{Plant material}

Young potato plants from the cultivar Agata were inoculated with PVY according to Noordam [25]. They were grown in greenhouse conditions. The two groups of potato plants (healthy and inoculated with PVY) were tested for PVY with DAS-ELISA (Double Antibody Sandwich Enzyme Linked Immunosorbent Assay) [26], [24] using sap from homogenized potato leaves. Tissue samples from healthy and infected plants were used. Micro titer ELISA plate wells were coated with the PVY IgG polyclonal antiserum diluted in $0.05 \mathrm{M}$ carbonate buffer ( $\mathrm{pH}$ 9.6) according to the supplier's specifications. Plates were incubated for $4 \mathrm{~h}$ at $37^{\circ} \mathrm{C}$, followed by 5 -minutes washing steps with PBS-T buffer and then loading with homogenized in coating buffer with 1\% PVP and albumin (BSA) plant extracts. After that plates were incubated at $4^{\circ} \mathrm{C}$ overnight. After washing off the crude plant extract, virus was detected by the PVY virus antibodies conjugated with alkaline phosphatase and diluted in conjugate buffer according to the supplier's specifications in incubation step for 4 $\mathrm{h}$ at $37^{\circ} \mathrm{C}$. P-nitro phenyl phosphate diluted in diethanolamin buffer (1 mg ml-1, $\mathrm{pH} 9.8)$ is a substrate for the alkaline phosphatase enzyme reaction which runs on room temperature and after coloring is stopped with $3 \mathrm{~N} \mathrm{NaOH}$. Optical density (OD) at wavelength $405 \mathrm{~nm}$ was measured by a Multifunctional detector DTX 880 (Beckman, USA). Positive results are those ones that exceed three times OD of the negative control.

\subsection{Leaf spectral reflectance}

The measurements of leaf reflectance are the base of an indirect remote sensing method, able to monitor vegetation conditions from a distance, and evaluate the spatial extent and patterns of vegetation characteristics and plant health [27]. Advanced HRS sensors afford new possibilities to disclose subtle changes in vegetation characteristics. The spectral properties of vegetation are strongly determined by their biophysical and biochemical parameters such as leaf area index (LAI), the amount live and senesced biomass, pigment and moisture content and spatial arrangement of cells and structures [28]. Leaves represent the main surfaces of plant canopies where energy and gas are exchanged. The general shape of reflectance and transmittance curves for green leaves is similar for all species. It is controlled by absorption features of specific molecules and the cellular structure of the leaf tissue [29]. Each spectral region provides unique information about the plant. For instance, the reflectance at VIS wavelengths is mainly function of leaf pigments, while the reflectance at NIR wavelengths depends of the internal mesophyll structure and moisture attributes of the leaves [30].

\subsection{Spectral measurements and data processing}

Hyperspectral reflectance data were collected by means of a portable fiber-optics spectrometer USB2000 (Ocean Optics, USA) in the VIS and NIR spectral ranges $(350-1100 \mathrm{~nm})$ in 2048 narrow spectral 
D. Krezhova et al., Remote Sensing of the Influence of Biotic Stress..., Rad. Applic., 2017, 2, 1, 46-52

bands with a spectral resolution of $1.5 \mathrm{~nm}$. The detector used is a high-sensitive 2048-elements CCD-array Spectrometer connects to a computer via the USB 2.0 port and stores a full spectrum into memory every msec [31]. The data analyses were performed in the spectral range $450-850 \mathrm{~nm}$ where the reflectance spectra of healthy and infected plants differed significant and give information about changes in the biochemical and biophysical attributes of the plants. The analysed spectral reflectance characteristics (SRC) of the plants were determined as a ratio between the reflected from the leaves radiation and this one reflected from the diffuse reflectance standard WS-1, (Lambertian material distinguished by its white matte finish and reflectivity $>98 \%$ in the range $250-1500$ $\mathrm{nm}$ ). Specialized software (OceanView) was used for data acquisition and data processing allowing spectroscopic measurements (such as absorbance, reflectance, and emission), control all system parameters, collect and display data in real time, and perform reference monitoring and time acquisition experiments [31]. The spectral measurements were carried out using a laboratory setup on fresh detached leaves on the third and the tenth day after the inoculation with PVY. The light source was a halogen lamp providing homogeneous illumination of the leaf surface. From a distance of $20 \mathrm{~cm}$ measured leaf area (pixel) was about $1.6 \times 2 \mathrm{~mm}$.

The analyses of the changes of the plants' SRC, connected to variation of some biophysical parameters (vegetation Chl absorption characteristics, vegetation moisture content, etc.), were performed in green (520$580 \mathrm{~nm})$, red $(640-680 \mathrm{~nm})$, red edge $(680-720 \mathrm{~nm})$ and NIR $(720-780 \mathrm{~nm})$ spectral ranges. The significance of the differences between SRC of healthy and infected leaves was assessed by means of statistical analysis (Student's t-test). It was performed in ten wavelengths $\left(\lambda_{1}=475.22 \mathrm{~nm}, \lambda_{2}=489.37 \mathrm{~nm}, \lambda_{3}=\right.$ $524.29 \mathrm{~nm}, \lambda_{4}=539.65 \mathrm{~nm}, \lambda_{5}=552.82 \mathrm{~nm}, \lambda_{6}=$ $667.33 \mathrm{~nm}, \lambda_{7}=703.56 \mathrm{~nm}, \lambda_{8}=719.31 \mathrm{~nm}, \lambda_{9}=724.31$ $\mathrm{nm}$, and $\left.\lambda_{10}=758.39 \mathrm{~nm}\right)$, chosen to be disposed uniformly in the investigated spectral ranges [32], [33]. The first derivative analyses were applied to evaluate the red edge position of the reflectance spectra.

Seven VI's were calculated for assessment of the physiological state of the infected plants [34], [35] as follows:

- NDVI - Normalized Difference Vegetation Index one of the most commonly used vegetation indices for biomass estimation or plant "greenness".

$$
\text { NDVI }=\left(R_{\text {NIR }}-R_{r e d}\right) /\left(R_{N I R}+R_{\text {red }}\right) \text {, }
$$

where: $\mathrm{R}$ is spectral reflectance in wavelengths at nir $=755 \mathrm{~nm}$ and red $=685 \mathrm{~nm}$;

- $\mathrm{f}_{\mathrm{D}}$ - Disease Index (specific for individual study)

$\mathrm{f}_{\mathrm{D}}=\mathrm{R}_{500} /\left(\mathrm{R}_{500}+\mathrm{R}_{570}\right)$;

- PRI - Photochemical Reflectance Index - an index of photosynthetic efficiency

$P R I=\left(R_{531}-R_{570}\right) /\left(R_{531}+R_{570}\right) ;$

- SR -Simple Ratio - the ratio of the wavelength with highest reflectance for vegetation and the wavelength of the deepest chlorophyll absorption. The simple equation is easy to understand and is effective over a wide range of conditions

$$
\mathrm{SR}=\mathrm{R}_{\mathrm{NIR}} / \mathrm{R}_{\text {red }}
$$

where: $\mathrm{NIR}=755 \mathrm{~nm}$ and red $=670 \mathrm{~nm}$;

- MSR - Modified Simple Ratio -it aims to increase sensitivity to vegetation biophysical parameters

$\operatorname{MSR}=\left(\mathrm{R}_{\mathrm{NIR}} / \mathrm{R}_{\text {red }}-1\right) /\left(\left(\mathrm{R}_{\mathrm{NIR}} / \mathrm{R}_{\mathrm{red}}\right)^{1 / 2}+1\right)$,

where: $\mathrm{NIR}=755 \mathrm{~nm}$, red $=685 \mathrm{~nm}$;

- NPCI - Normalized Pigment Chlorophyll Index

$\mathrm{NPCI}=\left(\mathrm{R}_{600}-\mathrm{R}_{460}\right) /\left(\mathrm{R}_{600}+\mathrm{R}_{460}\right) ;$

-TCARI - Transformed Chlorophyll Absorption Reflectance Index

$$
3\left(\left(\mathrm{R}_{700}-\mathrm{R}_{670}\right)-0,2\left(\mathrm{R}_{700}-\mathrm{R}_{550}\right)\left(\mathrm{R}_{700} / \mathrm{R}_{673}\right)\right) \text {. }
$$

The VI data set were processed by the method of analysis of variance using F-criterion for test significance and LSD values for statistical estimation of the significance of differences between variant means at $\mathrm{p}<0.05,0.01,0.001$ depending on data dispersion.

\section{RESULTS AND DISCUSSION}

The averaged SRC over all spectral measurements (up to 35 pixels) of control and infected with PVY potato leaves, cultivar Agata, conducted on the third day after the inoculation with PVY (Agata 1), are shown in Fig. 1.

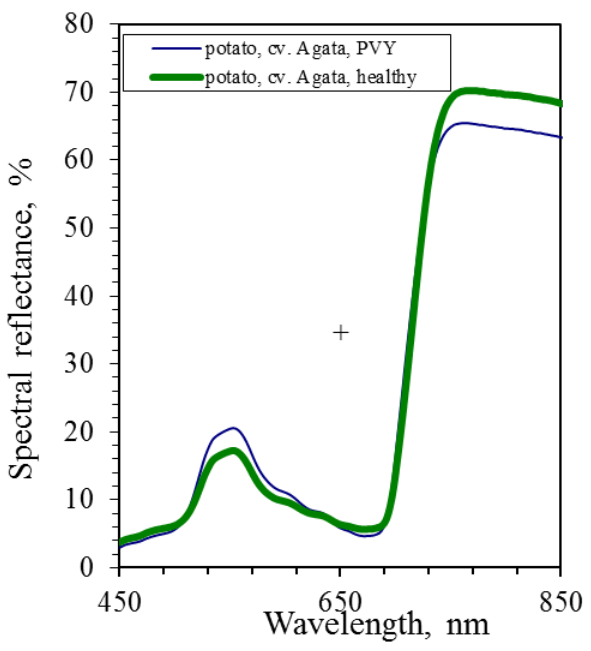

Figure 1. Averaged spectral reflectance characteristics of control and infected with PVY potato plants, cultivar Agata on the third day after the inoculation

The healthy leaves show high values of reflectance in the NIR and low values in the VIS part of the spectrum. The values of SRC of infected leaves differed against the healthy (control) in green, red and NIR spectral ranges. In the green range the values of the infected leaves are higher than the control. When plants are subjected to stress, the Chl content decreases and allows for the expression of other leaf pigments 
D. Krezhova et al., Remote Sensing of the Influence of Biotic Stress..., Rad. Applic., 2017, 2, 1, 46-52

such as carotenes and xanthophyll, causing a broadening of the green reflectance peak at $550 \mathrm{~nm}$ and an increase of reflectance in the VIS range. In the spectral range $640-680 \mathrm{~nm}$ the reflectance slightly decreases due to reduction of the pigment content.

In the NIR region the values of the SRC of the infected leaves are lower than the healthy ones due to changes in cell structure. In this range (700-1300 nm) leaf pigments and cellulose are almost transparent, so the absorption is very low and reflectance and transmittance reach their maximum values. This is caused by internal scattering at the air-cell-water interfaces within the leaves [36]. The level of a spectral reflectance on the NIR plateau increases with increasing number of inter-cell spaces, cell layers and cell size. When the plants are under conditions of stress these parameters decrease.

Fig. 2 shows the averaged SRC of control and infected with PVY potato leaves from cultivar Agata measured on the tenth day after the inoculation (Agata 2). The differences appeared in green and red spectral ranges and they are higher than the differences in the case of Agata 1. The changes in green and red ranges show that the reduction of the Chl content continues and the color of the leaves is progressively changing.

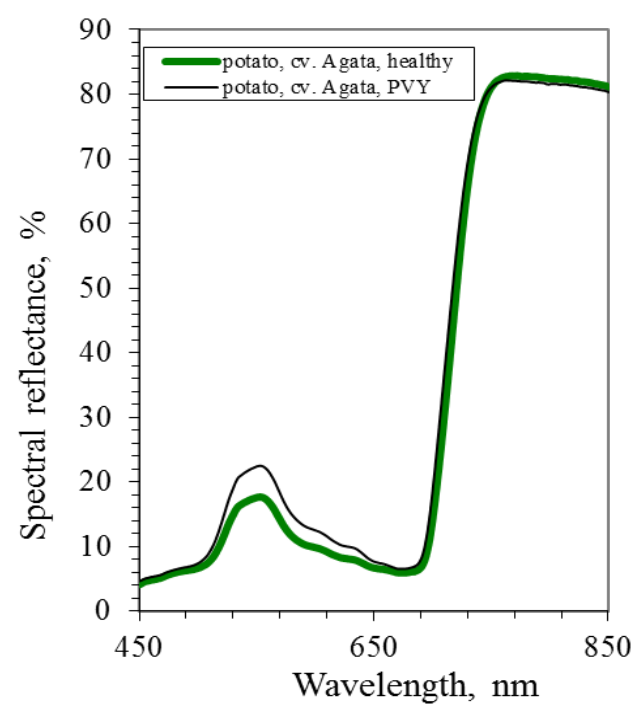

Figure 2. Averaged spectral reflectance characteristics of control and infected with PVY potato plants, cultivar Agata on the tenth day after the inoculation

Table 1. Means and p-values of the Student's t-test of SRC pairs of control and infected with PPV potato leaves cultivar Agata

\begin{tabular}{|c|c|c|c|c|c|c|}
\hline \multirow{2}{*}{$\begin{array}{c}\text { Pairs } \\
\text { compared }\end{array}$} & \multicolumn{3}{|c|}{ Agata 1 } & \multicolumn{3}{c|}{ Agata 2} \\
\cline { 2 - 3 } & Healthy & \multirow{2}{*}{$\mathrm{p}<$} & PPV & Healthy & \multirow{2}{*}{$\mathrm{p}<$} & PPV \\
\cline { 2 - 2 } \cline { 5 - 7 } & mean & & mean & mean & mean \\
\hline$R_{1} / R_{1 c}$ & 5.16 & $\mathrm{~ns}$ & 4.35 & 5.77 & $\mathrm{~ns}$ & 6.14 \\
\hline$R_{2} / R_{2 c}$ & 5.78 & $*$ & 4.98 & 6.37 & $* * *$ & 6.79 \\
\hline$R_{3} / R_{3 c}$ & 12.49 & $* * *$ & 14.77 & 12.91 & $* * *$ & 16.15 \\
\hline$R_{4} / R_{4 c}$ & 16.44 & $* * *$ & 19.60 & 17.10 & $* * *$ & 21.41 \\
\hline$R_{5} / R_{5 c}$ & 17.25 & $* * *$ & 29.55 & 17.97 & $* * *$ & 22.49 \\
\hline$R_{6} / R_{6 c}$ & 5.71 & $* * *$ & 4.74 & 6.20 & $*$ & 6.72 \\
\hline$R_{7} / R_{7 c}$ & 18.42 & $* * *$ & 22.03 & 19.64 & $* * *$ & 24.63 \\
\hline$R_{8} / R_{8 c}$ & 42.20 & $* *$ & 45.13 & 48.24 & $* *$ & 53.76 \\
\hline$R_{9} / R_{9 c}$ & 49.70 & $* *$ & 51.20 & 57.43 & $\mathrm{~ns}$ & 61.91 \\
\hline$R_{10} / R_{10 c}$ & 70.04 & $* * *$ & 65.41 & 82.79 & $\mathrm{~ns}$ & 81.96 \\
\hline
\end{tabular}

ns - no statistical significance; * - p $<0.05 ; * *$ - $p<0.01 ; * * *$ - $<<0.001$

In the NIR range the SRC values of infected leaves are close to the healthy ones which indicated the improvement of the cell structure and water content.

The results from statistical analyses are set in Table 1. In the first column of the table $\mathrm{R}_{\mathrm{i}} / \mathrm{R}_{\mathrm{ic}}(\mathrm{i}=1, \ldots, 10)$ designates that the data sets of spectral reflectance of the infected $\left(\mathrm{R}_{\mathrm{i}}\right)$ and the control $\left(\mathrm{R}_{\mathrm{ic}}\right)$ leaves are compared at the ten above listed wavelengths. In the case of potato plants Agata 1 the differences between means of sets of the SRC values of control and infected leaves are statistically significant in nine wavelengths. In the case of Agata 2 the differences are statistically significant at seven wavelengths indicating that the changes in SRC of infected leaves on the tenth day after the inoculation are decreased.

To assess the red edge position first derivative analyses were performed on the averaged SRC of Agata 1 and Agata 2. The calculated first derivatives are presented in Fig. 3. A shift to lower wavelengths is observed for SRC of infected leaves against the control SRC for Agata 1 and Agata 2 (about $12 \mathrm{~nm}$ and $7 \mathrm{~nm}$, respectively) which is an indicator for presence of stress in the plants resulting from arising changes in their physiological state, as well as the degree of the stress. This result complies with the conclusions from the statistical analyses.

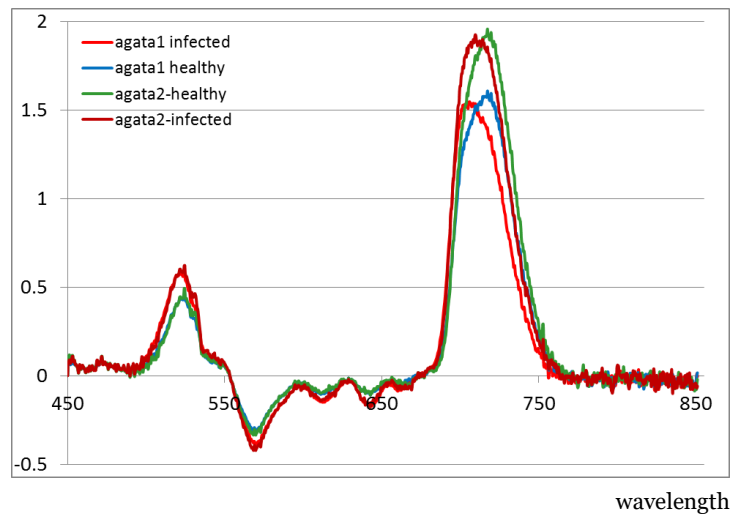

Figure 3. First derivatives on the averaged SRC healthy and infected potato leaves - Agata 1 and Agata 2 
D. Krezhova et al., Remote Sensing of the Influence of Biotic Stress..., Rad. Applic., 2017, 2, 1, 46-52

Results from DAS-ELISA test (Fig. 4) show presence of PVY in two infected groups of leaves. Extinction values for these samples were exceeding three times the negative control and they were considered as virus positive. The optical density OD at the wavelength of $405 \mathrm{~nm}$ goes down from 2.833 for Agata 1 to 1.547 for Afgata 2. The cut off value is 0.648 . The healthy (control) groups have extinction values near to the negative control (K-) - 0.218 for Agata 1 and 0.245 for Agata 2. Until the $10^{\text {th }}$ day after non-natural inoculation with PVY the potato plants remained symptomless independently of the presence of PVY. On the tenth day the OD for Agata 2 is lower.

Seven hyperspectral vegetation indices were computed (equations in subsection 2.3) for each set of spectral data. Table 2 shows the mean values of indices
NDVI, $f_{D}$, PRI, SR, MSR, NPCI, TCARI, standard deviations and statistical significance of differences. Student's t-test (at $\mathrm{p}<0.05$ ) was applied for assessment of the significance of differences between VI's values for control and infected leaves from plants Agata 1 and Agata 2. The best results for separating the healthy from infected leaves give the indices TCARI, SR and $f_{D}$ because their mean values for infected groups decreased in comparison with the values of control groups and the differences were statistically significant. The indices NDVI and PRI give dissimilar results and they are not efficient for estimation of changes in the spectral reflectance and biophysical variables caused by the PVY infection. NPCI and MSR gave contradictory results.

Table 2. Values of hyperspectral vegetation indices used in the study, $\mathrm{F}$-value and least significance difference (LSD) at level $\mathrm{p}=0.05$ (95\%)

\begin{tabular}{|l|l|l|l|l|l|l|l|}
\hline \multirow{2}{*}{ Potato leaves } & \multicolumn{7}{|c|}{ Vegetation indices } \\
\cline { 2 - 8 } & NDVI & $\mathrm{f}_{\mathrm{D}}$ & PRI & SR & MSR & NPCI & TCARI \\
\hline Healthy Agata 1 & 0.844 & 0.312 & 0.045 & 0.081 & 2.54 & 0.156 & 29.94 \\
\hline PPV Agata 1 & $0.854^{*}$ & $0.260^{* *}$ & $0.050^{*}$ & $0.071^{*}$ & $2.73 \mathrm{~ns}$ & $0.180 \mathrm{~ns}$ & $11.86^{* * *}$ \\
\hline Healthy Agata 2 & $0.844^{*} \mathrm{~ns}$ & $0.293^{*}$ & $0.045^{*}$ & 0.079 & 5.04 & 0.148 & 44.09 \\
\hline PPV Agata 2 & $0.861^{* *}$ & $0.324^{*}$ & $0.049^{*}$ & 0.072 & $2.88^{* *}$ & $0.145 \mathrm{~ns}$ & $10.24^{* *}$ \\
\hline F & 91.400 & 14.300 & 89.910 & 89.71 & 38.15 & 23.05 & 14.09 \\
LSD 0.05 & 0.009 & 0.026 & 0.003 & 0.007 & 1.08. & 0.07 & 0.907 \\
\hline
\end{tabular}

ns - no statistical significance; ${ }^{*}$ - $\mathrm{p}<0.05{ }^{* *}$ - $\mathrm{p}<0.01 ;{ }^{* * *}$ - $\mathrm{p}<0.001$

Visible symptoms of PVY infection were observed after the $20^{\text {th }}$ day consisting of chlorotic and necrotic patterns and leaf deformation.

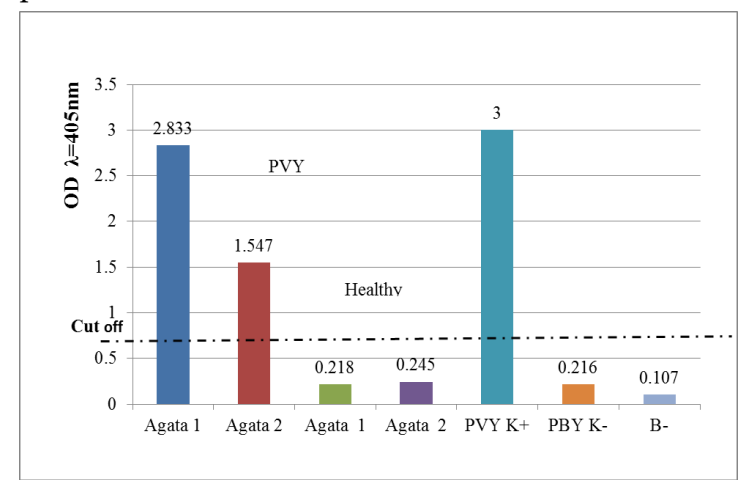

Figure 4. DAS-ELISA results for PVY infection of the potato plants cultivar Agata

Legend: 1 - potato plants cv. Agata 1 three days after the virus inoculation; 2 - potato plants cv. Agata 2 ten days after virus inoculation; 3 - healthy potato plants cv. Agata on the $3^{\mathrm{d}}$ day; 4 - healthy potato plants $\mathrm{cv}$. Agata on the $10^{\text {th }}$ day; 5 - Positive control for PVY from the kit; 6 - Negative control for PVY from the kit; 7 - Buffer control

\section{CONCLUSIONS}

Hyperspectral remote sensing measurements of leaf reflectance were applied for assessing the effect of a biotic stress (viral infection caused by Potato Virus Y) on biophysical and biochemical variables and spectral behaviour of crop plants (potato, cultivar Agata). Several data processing techniques such as Student's t- test, first derivative analyses, estimation of vegetation indices, analysis of variance, were applied to assessing the differences between the reflectance data of healthy and infected plants. In this regard consistent results were produced. In red edge region a shift of SRC values of the infected leaves for both Agata 1 and Agata 2 toward the lower wavelengths (about $12 \mathrm{~nm}$ and $7 \mathrm{~nm}$, respectively) was observed. So, the red edge position is reliable indicator for presence of changes in the physiological state of the plants and for detection of viral infection, as well as for the degree of the infection. The serological test DAS-ELISA was applied to detect and assess the quantity of the viruses and strong relationship was found between the results of this test and the findings of the spectral analyses.

These investigations emphasize the efficiency and sensitivity of the remote sensing of hyperspectral reflectance for monitoring of the natural resources and preservation of the Earth's ecosystems. Our results demonstrate the great potential of this method for assessing changes in various biophysical and biochemical properties of plants in response to the adverse environmental conditions (biotic stress), as well as for making timely management decisions for the rational use and preservation of the vegetable ecosystems.

\section{REFERENCES}

1. J. R. Jensen, Remote sensing of the environment: an earth resource perspective, Upper Saddle River (NY), USA: Prentice-Hall, 2000.

2. S. Sankaran, A. Mishra, R. Ehsani and C. Davis, "A review of advanced techniques for detecting plant diseases, Comput. Electron. Agric., vol. 72, pp. 1-13, 2010. 
DOI: 10.1016/j.compag.2010.02.007

3. K. Usha and B. Singh, "Potential applications of remote sensing in horticulture - A review," Sci. Horticul., vol. 153, pp. 71-83, 2013

DOI: $10.1016 /$ j.scienta.2013.01.008

4. A. A. Gitelson, "Wide dynamic range vegetation index for remote quantification of crop biophysical characteristics," J. Plant Physiology, vol. 161, pp. 165173, 2004.

DOI: $10.1078 / 0176-1617-01176$

PMid: 15022830

5. S. Stagakis, N. Markos, O. Sykioti and A. Kyparissis, "Monitoring canopy biophysical and biochemical parameters in ecosystem scale using satellite hyperspectral imagery: an application on a Phlomis fruticosa Mediterranean ecosystem using multangular CHRIS/PROBA observations," Remote Sens. Environ., vol. 114, pp. 977-994, 2010 DOI: $10.1016 /$ j.rse.2009.12.006

6. S. Delalieux, B. Somers, W. W. Verstraeten, J. A. N. Aardt, W. Keulemans and P. Coppin, "Hyperspectral indices to diagnose leaf biotic stress of apple plants considering leaf phenology," Int. J. Remote Sens., vol. 30, pp. 1887-1912, 2009. DOI: $10.1080 / 01431160802541556$

7. D. Moshou, C. Bravo, J. West, S. Wahlen, A. McCartney and $\mathrm{H}$. Ramon, "Automatic detection of yellow rust in wheat using reflectance measurements and neural networks," Comput. Electron. Agric., vol. 44, pp. 173188, 2004.

DOI: 10.1016/j.compag.2004.04.003

8. M. Prabhakar, Y. G. Prasad, M. Thirupathi, G. Sreedevi, B. Dharajothi and B. Venkateswarlu, "Use of ground based hyperspectral remote sensing for detection of stress in cotton caused by leafhopper (Hemiptera: Cicadellidae)," Comput. Electron. Agric., vol. 79, no. 2, pp. 189-198, Nov. 2011.

DOI: 10.1016/j.compag.2011.09.012

9. V. K. Shettigara, D. O'Mara, T. Bubner and S. G. Kempinger, "Hyperspectral Band Selection Using Entropy and Target to Clutter Ratio Measures," in Proc. of the 1oth Australasian Remote Sensing and Photogrammetry Conference, Adelaide, S. Aust., Australia: Causal Productions, 2000, pp. 1008-1018.

10. W. Zhang and S. Sriharan, "Using hyperspectral remote sensing for land cover classification," in SPIE Proc. 5655 Multispectral and Hyperspectral Remote Sensing Instruments and Applications II, 2005, pp. 261-270. DOI: $10.1117 / 12.578104$

11. J. L. Hatfield, A. A. Gitelson, J. S. Schepers and C. Walthall, "Application of spectral remote sensing for agronomic decisions," Agron. J., vol. 100, pp. S117S131, 2008. DOI: $10.2134 /$ agronj2006.0370c

12. I. Filella, A. Porcar-Castell, S. Munne-Bosch, J. Back, M. Garbulsky and J. Penuelas, "PRI assessment of longterm changes in carotenoids/chlorophyll ratio and short-term changes in de-epoxidation state of the xanthophyll cycle," Int. J. Remote Sens., vol. 30, pp. 4443-4455, 2009. DOI: $10.1080 / 01431160802575661$

13. J. B. Campbell, Introduction to Remote Sensing, London, UK: Taylor and Francis, 1996, p. 622.

14. G. R. Mahajan, R. N. Sahoo, R. N. Pandey, V. K. Gupta, and D. Kumar, "Using hyperspectral remote sensing techniques to monitor nitrogen, phosphorus, sulphur and potassium in wheat (Triticum aestivum L.)," Precision Agric, vol. 15, issue 2, pp. 227-240, 2014. DOI: $10.1007 / \mathrm{s} 11119-014-9348-7$

15. K. R. Manjunath et al., "Developing spectral library of major plant species of Western Himalayas using ground observations," J. Indian Soc. Remote Sens., vol. 42, no. 1, pp. 201-216, 2014.
DOI: $10.1007 / \mathrm{s} 12524-013-0305-0$

16. J. R. Jensen, Remote sensing of the environment: an earth resource perspective, Upper Saddle River (NY), USA: Prentice Hall, 2007.

17. R. Ranjan, U. K. Chopra, R. N. Sahoo, A. K. Singh and S. Pradhan, "Assessment of plant nitrogen stress through hyperspectral indices," Int. J. Remote Sens. vol. 22, issue 20, pp. 6342-6360, 2012 DOI: $10.1080 / 01431161.2012 .687473$

18. Y. M. Govaerts, M. M. Verstraete, B. Pinty and N. Gobron, "Designing optimal spectral indices: A feasibility and proof of concept study," Int. J. Remote Sens., vol. 20, pp. 1853-1873, 1999. DOI: $10.1080 / 014311699212524$

19. I. Filella and J. Penuelas, "The red edge position and shape as indicators of plant chlorophyll content, biomass and hydric status," Int. J. Remote Sens., vol. 15, no. 7, pp. 1459-1470, 1994. DOI: $10.1080 / 01431169408954177$

20. J. G. Clevers, S. M. De Jong, G. F. Epema, F. Van der Meer, W. Bakker and A. K. Skidmore, "Derivation of the red edge index using MERIS standard band setting", Int. J. Remote Sens., vol. 23, no. 16, pp. 3169-3184, 2002.

DOI: $10.1080 / 01431160110104647$

21. H. Ross, "Potato breeding: problems and perspectives," J. Plant Breeding, Supplement 13: Advances in Plant Breeding, Berlin and Hamburg, Germany: Parey, pp. 66-75, 1986.

22. T. Valkonen, "Viruses: Economic losses and biotechnological potential," in: Potato biology and biotechnology - advances and perspectives, eds. D. Vreugdenhil, E. J. Bradshow, Oxford, UK: San Diego (CA), USA: Elsevier, 2007, pp. 619-641.

23. J.A. de Bokx and H. Huttinga, "Potato virus Y. CMI/AAB", in Descriptions of Plant Viruses, Commonwealth Agricultural Bureaux/Association of Applied Biologists, No. 242, 1981.

24. N. Petrov, "Potato virus Y (PVY) in crop species from the family Solanaceae," Ph. D. dissertation, ISSAPP “N. Pushkarov", Sofia, Bulgaria, 2012.

25. D. Noordam, Identification of plant viruses: Methods and experiments, Wageningen, The Netherlands: Centre for Agricultural Publishing and Documentation, 1973, p. 207.

26. M. Clark and A. Adams, "Characteristics of the microplate method of enzyme linked immunosorbent assay for the detection of plant viruses," J. Gen. Virol., vol. 34 , pp. 475-483, 1977

DOI: $10.1099 / 0022-1317-34-3-475$

PMid: 323416

27. G. P. Asner, "Biophysical and biochemical sources of variability in canopy reflectance," Remote Sens. Environ., vol. 64, no. 3, pp. 234-253, Jun. 1998.

28. P. S. Thenkabail, R. B. Smith and E. Pauw, "Hyperspectral vegetation indices and their relationships with agricultural crop characteristics," Remote Sens. Environ., vol. 71, pp. 158-182, 2000. DOI: 10.1016/Soo34-4257(99)00067-X

29. S. L. Ustin, D. A. Roberts, R. O. Green, R. J. Zomer and M. Garcia, "Remote sensing methods monitor natural resources", Photon. Spectra, vol. 33, no. 10, pp. 108$113,1999$.

30. B. Pinty, T. Lavergne, J. L. Widlowsky, N. Gobron and M. M. Verstraete, "On the need to observe vegetation canopies in the near-infrared to estimate visible light absorption", Remote Sens. Environ., vol. 113, pp. 1023, 2009. DOI: 10.1016/j.rse.2008.08.017

31. http://www.oceanoptics.com

32. D. Krezhova, T. Yanev, St. Lukov, P. Pavlova, V. Aleksieva, D. Hristova and S. Ivanov, "Method for detecting stress induced changes in leaf spectral 
D. Krezhova et al., Remote Sensing of the Influence of Biotic Stress..., Rad. Applic., 2017, 2, 1, 46-52

reflectance," C. R. Acad. Bulg. Sci., vol. 58, no 5, pp. 517-522, 2005.

33. D. D. Krezhova, N. M. Petrov and S. N. Maneva, "Hyperspectral remote sensing applications for monitoring and stress detection in cultural plants: viral infections in tobacco plants," in Proc. of Remote Sensing for Agriculture, Ecosystems, and Hydrology Conf., Edinburgh, UK, 2012, vol. 8531, pp. 24-27.

DOI: $10.1117 / 12.974722$

34. P. S. Thenkabail, R. B. Smith and E. Pauw, "Hyperspectral vegetation indices and their relationships with agricultural crop characteristics," Remote Sens. Environ., vol. 71, pp. 158-182, 2000.

DOI: 10.1016/So034-4257(99)00067-X
35. Y. Lee, C. Yang, K. Chang and Y. Shen, "A simple spectral index using reflectance of $735 \mathrm{~nm}$ to assess nitrogen status of rice canopy," Agron. J., vol. 100, pp. 202-212, 2008.

DOI: 10.2134/agrojnl2007.0018

36. J. Hunt, E. Ramond and B. N. Rock, "Detection in changes in leaf water content using near and midinfrared reflectance," Remote Sens. Environ., vol. 30 no 1, pp. 43-54, Oct. 1989.

DOI: 10.1016/0034-4257(89)90046-1 